\title{
Effectiveness and Organization of Addiction Medicine Training Across the Globe
}

\author{
Astri Parawita Ayu ${ }^{a, d} \quad$ Arnt F.A. Schellekens ${ }^{b, d}$ Shelly Iskandar ${ }^{c}$ Lucas Pinxten $^{d}$ \\ Cor A.J. De Jong ${ }^{\text {d }}$ \\ ${ }^{a}$ Atma Jaya Catholic University of Indonesia, School of Medicine, Jakarta, Indonesia; ${ }^{b}$ Radboud University Medical Centre, \\ Department of Psychiatry, Nijmegen, The Netherlands; 'Padjajaran University/Hasan Sadikin Hospital, Department of \\ Psychiatry, Bandung, Indonesia; ${ }^{d}$ Radboud University, Nijmegen Institute for Scientist-Practitioners in Addiction (NISPA), \\ Nijmegen, The Netherlands
}

\section{Key Words}

Addiction training - Medical education - Curricula .

Substance abuse $\cdot$ Addiction medicine

\begin{abstract}
Background: Over the past decade, addiction medicine training curricula have been developed to prepare physicians to work with substance use disorder patients. This review paper aimed at (1) summarizing scientific publications that outline the content of addiction medicine curricula and (2) evaluating the evidence for efficacy for training in addiction medicine. Methods: We carried out a literature search on articles about addiction medicine training initiatives across the world, using PubMed, PsychINFO and EMBASE with the following search terms 'substance abuse, addiction medicine, education and training.' Results: We found 29 articles on addiction medicine curricula at various academic levels. Nine studies reported on the need for addiction medicine training, 9 described addiction medicine curricula at various academic levels, and 11 described efficacy on addiction medicine curricula. Conclusions: Several key competences in addiction medicine were identified. Efficacy studies show that even short addiction medicine training programs can be effective in improving knowledge, skills and attitudes related to addiction medicine. A more uniform approach to addiction medicine training in terms of content and accreditation is discussed.
\end{abstract}

ㄷ 2015 S. Karger AG, Basel
(C) 2015 S. Karger AG, Basel

$1022-6877 / 15 / 0215-0223 \$ 39.50 / 0$

\section{Introduction}

Over the past decades, the medical concept of substance use disorders (SUDs) has become more prominent [1]. SUDs are nowadays considered a chronic relapsing brain disease involving biological, psychological and social factors [2]. Moreover, alcohol abuse and SUDs have become one of the world's leading causes of health problems [3]. The annual prevalence of (illicit) drug use and abuse among the adult population worldwide is estimated at up to $4-5 \%$ for alcohol, $5 \%$ for cannabis, $1 \%$ for opioids and amphetamine type stimulants and $0.5 \%$ for cocaine, and substance use is reported as the cause of death in about 1 among every 100 deaths [4]. Similarly, abuse of prescription has also increased rapidly over the past decade, particularly in the United States (US) and the United Kingdom (UK) [5, 6]. Degenhardt reported that illicit substance use caused 20 million Disability Adjusted Life Years (DALYs) in 2010 (0.8\% of global all-cause DALYs) [7].

SUDs are often complicated by other conditions, including other psychiatric disorders and physical complications $[3,4,8,9]$. The most common co-occurring psychiatric disorders are mood disorders (25-42\%), attention deficit hyperactivity disorder (26-41\%), conduct disorder $(60 \%)$, psychotic disorders $(28 \%)$ and anxiety disorders (17-23\%) [3, 8-11]. Commonly reported phys-

\section{KARGER 125}

E-Mail karger@karger.com

www.karger.com/ear
Astri Parawita Ayu

Radboud University/ACSW NISPA

Postbus 6909

6503 GK Nijmegen (The Netherlands)

E-Mail parawitayu@gmail.com, a.ayu@psych.ru.nl 
ical complications include hepatitis C (47\%), HIV (20\%) and hepatitis $\mathrm{B}(15 \%)$ among injecting drug users [4], and liver cirrhosis (6-41\%) [12], cardiac complications (2.5$5.3 \%)[13,14]$ and neurological complications (10-21\%) among alcohol-dependent patients [15-17].

Given the extensive range of medical complications and comorbidity that often accompany SUDs, all medical doctors need some basic competence in the assessment and management of SUD patients [18, 19]. Moreover, it is highly important that medical doctors recognize the abuse of prescription drugs, and their role in degrading the health of the population [5]. Moreover, a subset of SUD patients will need medical attention from welltrained specialists in addiction medicine, like addiction specialists or addiction psychiatrists.

However, not all medical doctors consider SUDs a medical condition, and as such do not consider treatment of these patients as their domain of treatment [18, 20-28]. Moreover, it has been shown that negative perceptions of patients with SUDs, for example, considering them as criminals, dangerous or treatment resistant, fuel negative attitudes toward these patients [20-22, 29]. Indeed, stigma toward these patients among medical doctors as well as the general public, is a major challenge in dealing with SUD patients [30, 31]. Furthermore, medical doctors often lack knowledge and skills required for the assessment and treatment of SUD patients $[22,32]$. These factors undermine the quality of care for these patients with often high treatment needs.

Appropriate training can help to prepare medical doctors for working with SUD patients [25, 26, 33-35]. Several studies have shown that even short courses could increase knowledge on addiction medicine [36-40]. Moreover, courses have also been shown to induce more professional perceptions of and attitude toward patients with SUDs [36-39, 41-44]. These studies cover the full range of undergraduate level $[32,36,38,40]$, general physician level [37, 39, 40, 42-45] and addiction specialist level [41]. However, several questions remain unanswered: What teaching methods are most effective in improving knowledge, skills and attitude related to addiction medicine and what should an addiction medicine curriculum comprise? What addiction medicine competencies are required at the undergraduate and postgraduate levels?

The objective of the current study was to provide an overview of scientific publications on existing initiatives on the development of addiction medicine curricula at different educational levels worldwide. More specifically, our review papers aimed at (1) summarizing scientific

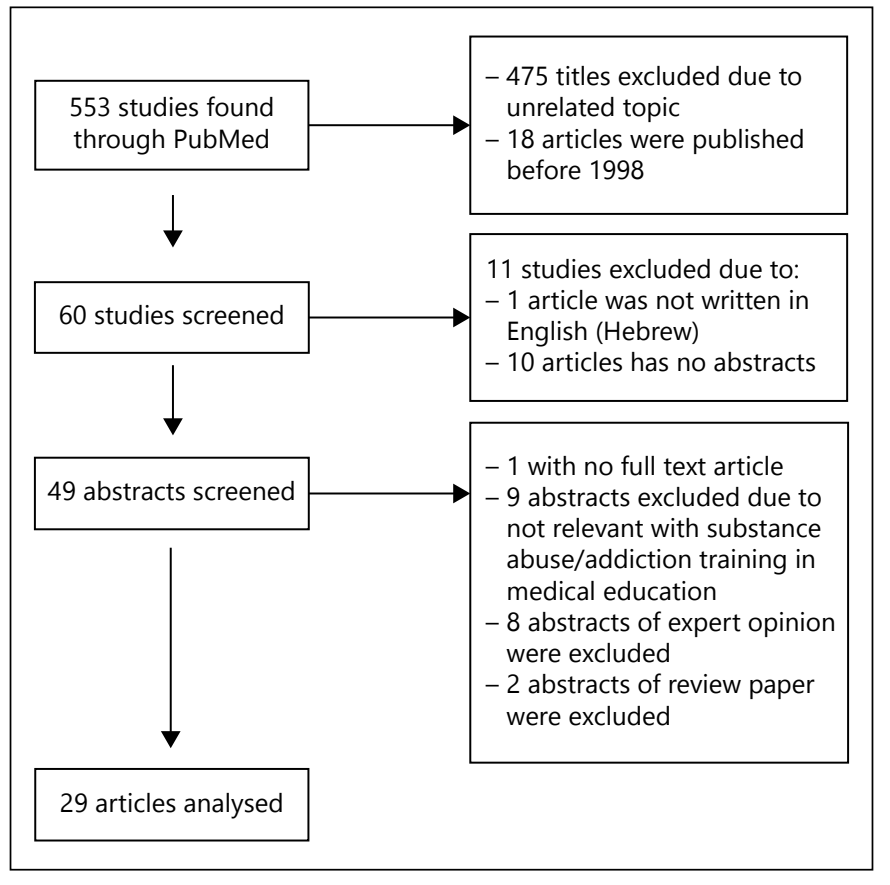

Fig. 1. Flowchart of the process of literature search.

publications that outline the content of addiction medicine curricula and (2) evaluating the evidence for efficacy for training in addiction medicine. Lessons learned from these experiences will be discussed, as well as recommendations for the development addiction medicine training at different academic levels.

\section{Methods}

Design

We performed a narrative literature review, following the ESRC Narrative Synthesis Guidance [46]. We used Pubmed, PsychINFO and EMBASE as search engines.

\section{Search Strategy}

We searched Pubmed, PsychINFO and EMBASE for articles on addiction medicine training published between 1998 and 2013, in English language. The following search terms were used: 'substance abuse, addiction medicine, education and training.' All articles about addiction medicine training initiatives across the world at any educational level within the medical curriculum were included.

\section{Selection of Papers}

The process of the literature research is summarized in figure 1 (flow chart). The search resulted in 553 results. The first author (AA) excluded articles with a title unrelated to substance use disorders or medical training. Titles referring to non-medical education were also excluded. This resulted in 60 articles for our review. 
The first and second author (AA and AS) screened the abstracts of these 60 articles. Of these, 21 articles had to be excluded: 1 article was written in Hebrew, 9 articles were not related to addiction medicine training, 10 articles had no abstract, and from 1 article we could not obtain a full text version. Eight papers were opinion statements from experts in the field related to addiction medicine training. In line with the Narrative Synthesis Guidance, we considered these papers not scientific evidence. Hence, these papers were excluded. Two papers were review papers $[18,19]$ and so they too were excluded, in line with the guidelines for narrative reviews. Finally, we were left with 29 articles for analysis.

\section{Results}

Of the 29 articles included in this review, nine studies reported on surveys on the need for addiction medicine training (table 1) [23, 24, 27, 47-52]. These studies did not relate directly to the specific objectives of our study. However, these studies did emphasize the need to develop addiction medicine curricula. Therefore, we summarized these papers shortly in table 1 and in the Results section later in this article. In line with objective 1 , nine descriptive studies outline initiatives on addiction medicine curricula at various academic levels [53-61]. These studies are summarized in table 2 and discussed later in this article. Efficacy studies on addiction medicine curricula $(\mathrm{n}=11)$ answer objective 2 and are summarized in table 3 [32, 36-45].

Over the past fifteen years, the number of publications related to addiction medicine training has increased gradually. Six of the 29 published articles on training in addiction medicine included in this review were published between 1998 and 2003, ten between 2003 and 2008 and 13 between 2008 and 2013. Of particular interest is the special issue on training in addiction medicine published by Substance Abuse in 2011, where several addiction medicine curricula from various countries were outlined $[23,52,59-61]$.

\section{Survey Studies on the Need for Addiction Medicine Training}

The nine papers that describe the training needs for training in addiction medicine cover a broad range of survey studies from undergraduate to postgraduate level (table 1). These papers point out a lack of addiction medicine teaching at the undergraduate level. At the post graduate level, addiction medicine training is generally available within psychiatry and family medicine [47]. However, in almost half of other postgraduate medical training curricula, no time is allocated to topics related to addiction medicine [47]. All studies found that faculties consider addiction medicine training highly relevant, but at the same time report a lack of availability of adequate training programs [23, 24, 27, 47-52].

Two studies surveyed knowledge, skills and attitudes of medical students and clinicians to provide treatment for patients with SUDs $[24,27]$. The results of these studies suggest that addiction medicine training at undergraduate level can still be improved, in order to improve care for patients with substance use disorders by general physicians.

A cross-sectional survey among 1st-5th year medical students $(n=19,526)$ in 27 of 36 medical schools in Germany showed that students scored high on knowledge about addiction medicine, but most (40-60\%) reported that they did not know how to treat substance use disorder patients [27]. This survey included a comparison with other chronic conditions (hypertension and diabetes mellitus). Students were more self-confident treating these conditions than patients with SUDs. This survey also showed that teaching hours allocated for addiction medicine training are half compared to topics like diabetes and hypertension. A limitation of this study was the low response rate among the students (49.6\%). This may have induced a bias in the results, reducing generalizability of findings.

A cross-sectional survey among family physicians ( $\mathrm{n}=$ 150) and medical students $(\mathrm{n}=206)$ from three medical schools in Florida indicated poor knowledge on addiction medicine, as indicated by low scores on a written exam about alcohol use disorders [24]. The sample of family physicians and students was not described in detail. Therefore, it is hard to interpret the results and assess generalizability. Yet, the authors do emphasize that family physicians are particularly relevant in early detection and treatment of SUDs and should do better on the exam.

Four studies explored addiction medicine training needs in specialist training. All studies described limited time allocated for training in addiction medicine in postgraduate medical specialist training (preventive medicine, family medicine, emergency medicine, osteopathy medicine, internal medicine, obstetric and gynecology, pediatric, psychiatry, and child adolescent psychiatry) $[47,48,50,51]$.

Fleming et al. conducted a national survey in the United States about resident training in addiction medicine [47]. The study involved 1,831 residency directors from 7 specialist training programs (family medicine, psychiatry, internal medicine, pediatrics, obstetric and gynecology, emergency medicine, and osteopathy). They filled in a questionnaire regarding the availability of addiction medicine training, including the name and telephone number 


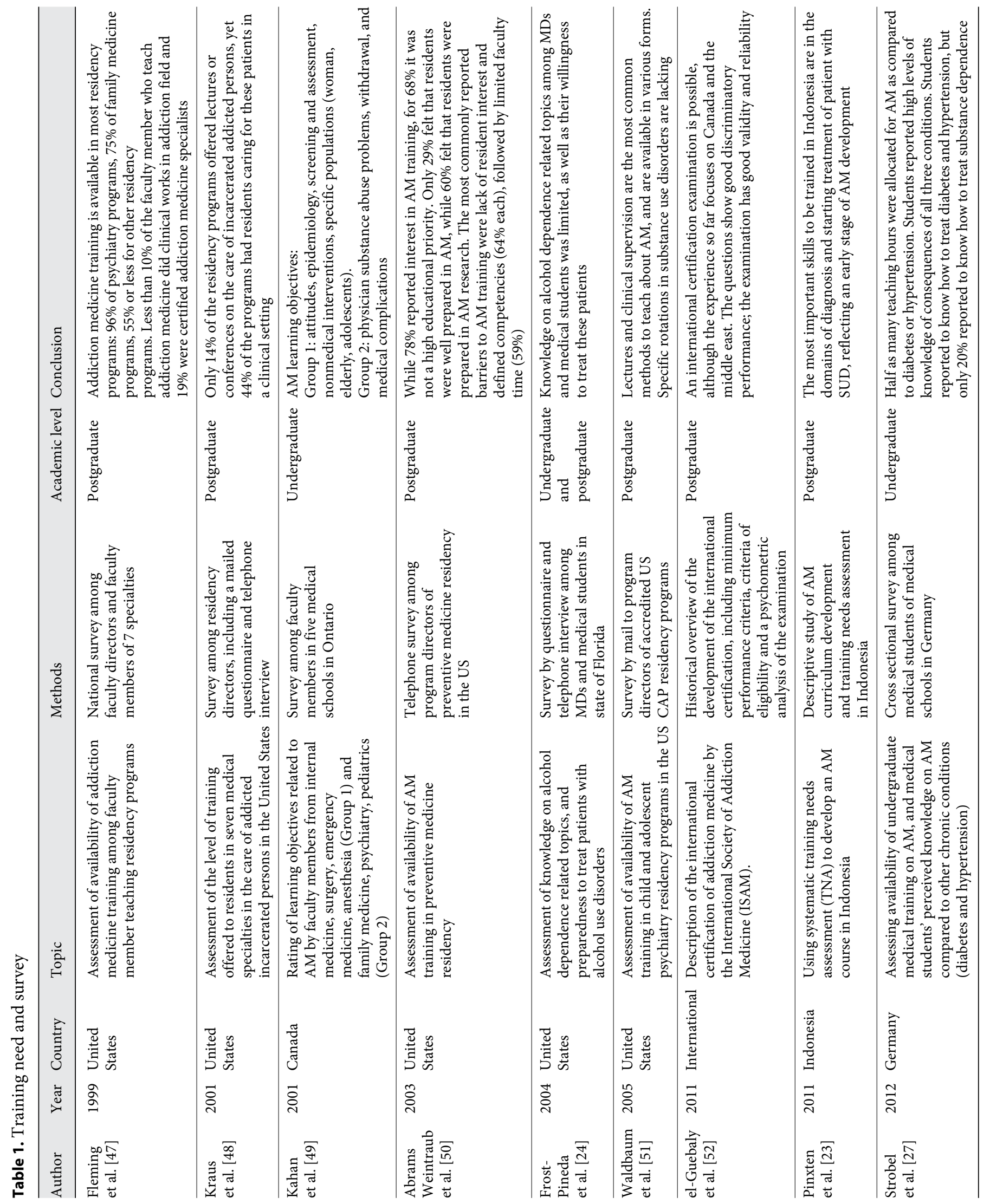




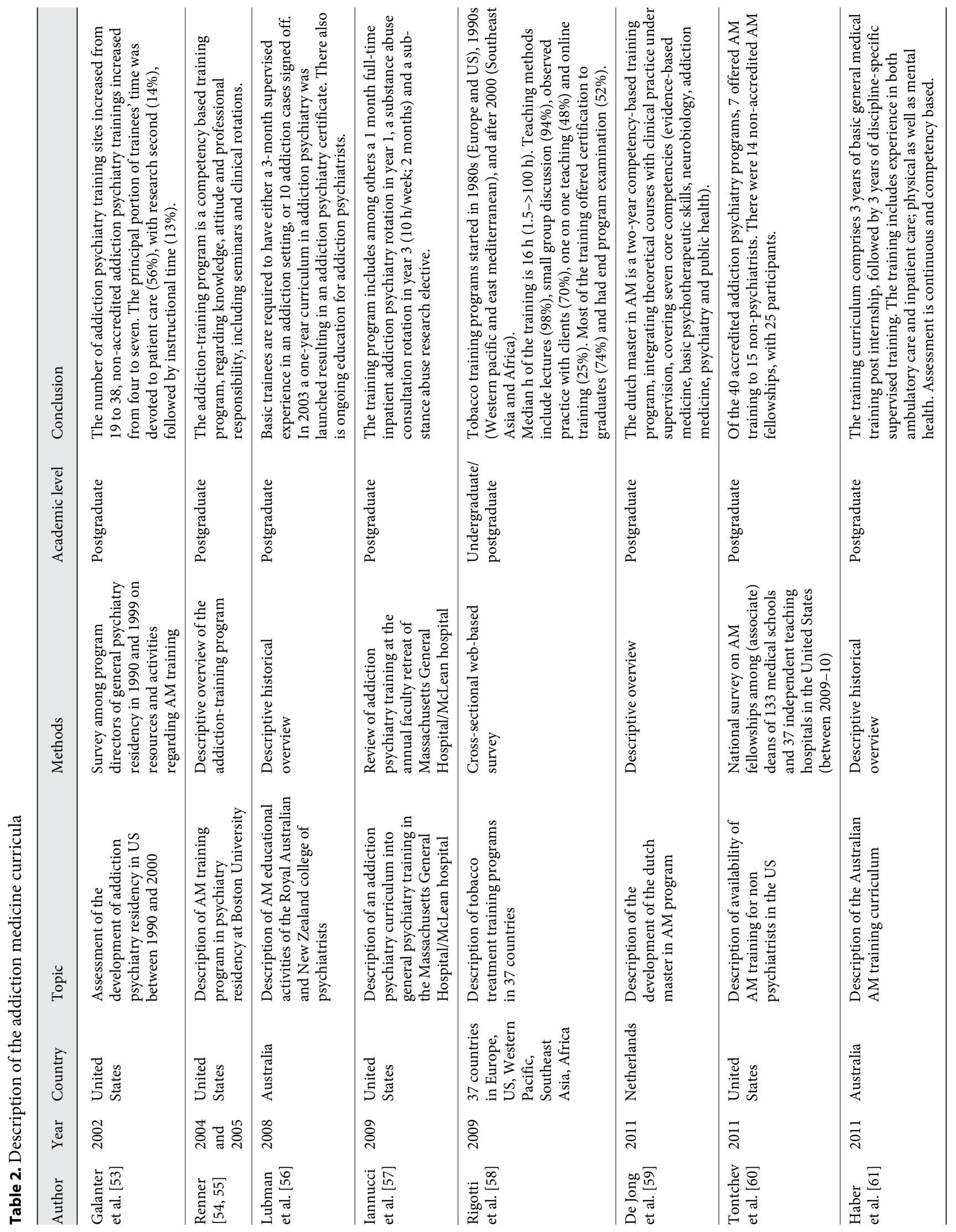


Table 3. Basic addiction medicine competence for general physicians

\begin{tabular}{ll}
\hline Competences & Topics \\
\hline Screening, prevention, and brief intervention & $\begin{array}{l}\text { Detect risk of alcohol and substance use, abuse, and addiction } \\
\text { Interview of alcohol and substance use history } \\
\text { Education and communication of the consequences of alcohol and substance use } \\
\text { (patient, family, and public) } \\
\text { Brief intervention to stop or reduce alcohol and substance use }\end{array}$ \\
\hline Assessment and diagnosis & $\begin{array}{l}\text { Interview of alcohol and substance use history } \\
\text { Physical examination of intoxication and withdrawal symptoms }\end{array}$ \\
\hline Management & $\begin{array}{l}\text { Management of intoxication and withdrawal symptoms } \\
\text { Develop relevant treatment plans (from initial treatment until relapse management) } \\
\text { Prescribing drugs (including drugs with abuse potential) } \\
\text { Referral }\end{array}$ \\
\hline Complications & $\begin{array}{l}\text { Assessment, management, and referral of medical, surgical, and psychiatric } \\
\text { complications related to SUDs }\end{array}$ \\
\hline Special populations & $\begin{array}{l}\text { Screening, brief intervention, assessment and diagnosis, management of SUD } \\
\text { problems in special populations }\end{array}$ \\
\hline Epidemiology and scientific aspects & $\begin{array}{l}\text { Epidemiology } \\
\text { Neuroscience and genetics }\end{array}$ \\
\hline
\end{tabular}

of the responsible faculty member. Those faculties with clear addiction medicine training (769) were interviewed by telephone in a semi-structured interview.

Addiction medicine training was mostly available in residency programs for psychiatry $(96 \%)$ and family medicine (75\%). For other residency training programs, $55 \%$ or less had training in addiction medicine. Less than $10 \%$ of the faculty members who taught addiction medicine did clinical work in the addiction field and $19 \%$ were certified addiction medicine specialists. The faculty members interviewed in this study were identified by faculty directors. There was no further description of the participating institutions, faculty directors and faculty members. Moreover, the number of respondents from each specialism is highly variable $(28-270)$. Therefore, a selection bias cannot be ruled out. There is also no clear description of the questionnaire and telephone interview, making interpretation of the results difficult.

The part of the interviews that focused on incarcerated SUD patients was published in a separate paper by the same group [48]. Only $14 \%$ of the residency programs offered lectures or conferences on the care of incarcerated addicted persons, yet $44 \%$ of the programs had residents caring for these patients in a clinical setting. Twenty two percent of the interviewed faculty members provided the opportunity for their residents to have clinical experiences in correctional facilities.
Another telephone survey among preventive medicine residency program directors in the United States $(n=41)$, showed a scarcity of addiction topics, especially about alcohol and other drugs [50]. While $78 \%$ reported interest in addiction medicine training, for $68 \%$ it was not a high educational priority. Only $29 \%$ felt that residents were well prepared in addiction medicine. Most of the existing addiction topics focused only on tobacco. Though the study had a $100 \%$ response rate, the methodology applied has some limitations. First, the telephone interview was unstructured. Second, no descriptive data were available on the participants (faculty members, preventive medicine programs).

A cross-sectional survey, using self-report questionnaires, was performed among program directors $(n=79)$ of child and adolescent psychiatry training in the United States [51]. This study showed that almost all child and adolescent psychiatry training programs had lectures and clinical supervision as the most common methods to teach about addiction medicine. However, specific rotations in addiction medicine were mostly lacking. The response rate of the study was rather good $(70 \%)$, but the authors did not report any characteristics of responders and non-responders. This may have induced a bias, in a way that program directors who did not return the survey may have had programs lacking addiction medicine training. 
In the four studies summarized earlier, several barriers in developing addiction medicine training in medical education were identified $[47,48,50,51]$ with the most important being limited availability of curricular time, poor coordination of the addiction medicine theme between different departments involved in the medical faculty, lack of addiction treatment facilities that can be used as education sites for clinical experiences and insufficient faculty members interested and qualified in teaching about addiction medicine.

One survey study evaluated the perceived relevance of a list of learning objectives related to addiction medicine among faculty members $(n=68)$ in five medical schools in Ontario, Canada [49]. The set of learning objectives used was developed by the medical educators and addiction medicine specialists from the project Curriculum Renewal and Evaluation of Addiction Training and Education (CREATE) and represents knowledge, skills, and attitudes [49]. The learning objectives considered most important were professional attitudes toward SUD patients, epidemiology of substance use disorders, screening and assessment of patients with substance use disorders, non-medical interventions in substance use disorder patients, specific populations with substance use disorders (woman, elderly, adolescents), physician substance abuse problems, dealing with withdrawal and medical complications of substance use [49]. Since only faculty members of five medical schools in Canada were assessed, the results may not be generalized to medical schools in general. Moreover, the perspective of students and patients was lacking in this study.

One study described the results of a systematic training needs assessment (TNA) in Indonesia [23]. The TNA questionnaire had three professional domains modeled on the National Institute of Drug Abuse (NIDA) training needs assessment tool [23]. The most important skills to be trained in Indonesia identified in this study were in the domains of diagnosis and starting treatment of patient with substance use disorders. The authors suggest that this may reflect an early stage of addiction medicine development, since skills required for long-term management of these patients were rated less important.

Finally, one paper described the process of international examination on addiction medicine [52]. The International Society of Addiction Medicine (ISAM) gave a great impulse for development of addiction medicine curricula worldwide, by the initiative for an international addiction medicine examination. This examination comprises a test of knowledge and clinical judgment, consisting of 200 'culture-neutral' multiple-choice questions

Effectiveness and Organization of

Addiction Medicine Training
[52]. The results from the first batch of candidates revealed that formulation of international examination standards is possible. However, these results are mainly based on experiences in Canada and the Middle East, reducing generalizability.

\section{Description of Addiction Medicine Curricula}

We found nine articles describing national initiatives on the development of addiction medicine curricula. These curricula vary widely in terms of organization, certification and content, and are summarized in table 2 .

Two papers describe the development of the addiction medicine curriculum at the University of Boston [54, 55]. These articles present the model for enhanced addiction psychiatry training developed at Boston University Medical Centre. They chose to integrate addiction medicine training with general psychiatry residency. The cornerstones of the addiction medicine curriculum are adequate knowledge, a positive attitude toward SUD patients and their treatment, and professional responsibility [54, 55]. It includes skills training labs, followed by a longterm rotation in an addiction psychiatry unit to acquire clinical competencies, such as motivational interviewing, cognitive behavioral therapy, pharmacotherapy and assessment $[54,55]$.

A similar four-year psychiatry residency program is offered by the Massachusetts General Hospital [57]. The number of formal addiction psychiatry training sites in United States has increased to about forty in $2011[53,60]$. Moreover, these training programs offered addiction medicine training to non-psychiatrist in some cases [60].

In Australia, addiction medicine training is offered as a three-year course, after a three-year basic training in internal medicine [61]. In the Netherlands, a two-year national curriculum on addiction medicine has been developed [59]. This training program is unrelated to psychiatric training and is open to all medical doctors.

The formal legislation of addiction medicine is highly variable among countries, ranging from none, to formal expert registrations. Addiction medicine is recognized as a medical specialty in Australia and New Zealand [56, 61]. In the United States, addiction psychiatry has been formally acknowledged as a subspecialty of psychiatry [53]. In the Netherlands, completion of the addiction medicine curriculum results in registration as an addiction medicine expert by the Dutch Society of Medicine [59].

One paper reported a description of training programs on tobacco treatment for medical doctors in 48 countries [58]. Only 37 of the 48 responding countries had training in tobacco treatment. Most of the trainees in 
those training programs were physicians and medical students (90). Teaching methods used were lectures (98\%), small group discussions (94\%), one-on-one teaching (48\%) and online training (25\%). The median duration of these programs was $16 \mathrm{~h}$. The tobacco treatment training programs were mostly available in the middle and upper income countries. The survey recommended that similar training programs be developed for low-income countries [58]. The authors emphasized that their results may have been biased, because participating country representatives were selected based on previous surveys in this topic and people from the network of the others. Moreover, only 48 of 69 countries surveyed responded in this study.

The papers describing addiction medicine curricula summarized earlier also outline competencies that medical doctors should acquire during (undergraduate) training. Based on all of those studies, the addiction medicine competencies cover the following four domains: screening, prevention and brief interventions of substance use disorders; assessment and diagnosis of substance use disorders; management and treatment of substance use disorders; assessment, management, and referral of medical, surgical, and psychiatric complications related to alcohol and substance use disorders (see table 3 for further details).

\section{Effect of Studies of Training in Addiction Medicine}

The eleven studies that investigated the efficacy of addiction medicine training programs generally showed that most courses could increase knowledge and skills related to addiction medicine. Moreover, courses also induced more professional perceptions of, and attitudes toward patients with SUDs. Those papers are summarized in table 4.

Three studies assessed the effect of addiction medicine training at undergraduate level $[32,36,38]$. Christison et al. evaluated the perception and attitude among thirdyear medical students toward alcohol dependence, major depressive disorder, and severe emphysema using a selfreport questionnaire, before and after a psychiatric clerkship rotation (5 weeks psychiatry and 1 week SUDs). They observed that a one-week rotation at an SUDs treatment site led to a more professional perception of SUDs, as indicated by an increase in perceiving SUDs as a treatable condition, that requires medical treatment [36]. Similar changes were observed with regard to major depression, but not emphysema. No difference was found between students who took their psychiatric rotation in the first or second part of their clinical year. It is unclear whether the observed changes toward SUD patients really reflect a change in clinical behavior of these students toward SUD patients. Moreover, it is unknown how long these effects of clinical rotations endured.

Similarly, Barron et al. observed that participants of a summer school for recently graduated medical students $(n=245)$ had an increased perception that they $(n=140)$ could help patients with SUDs, that they were more selfconfident in talking to and treating of patients with SUDs, that SUDs is a disease and that working with patients with SUDs is satisfying, compared to students who did not attend the course $(n=105)$ [38]. The authors emphasized that their results may have been biased, since the summer school SUDs program was elective and students who followed the program might already have had more positive attitudes compared to other students. Moreover, given the cross-sectional design the observed difference between the two groups could not be attributed directly to an effect of the training.

A 4-year prospective cohort study followed medical students from all 4 New Zealand schools of medicine (Auckland, Wellington, Christchurch and Dunedin), during their undergraduate training [32]. Knowledge, attitudes and skills related to addiction medicine were assessed, using a questionnaire adapted from the questionnaire developed by Roche et al. [62]. The measurement was carried out during the second year and was repeated at year four and six. The students showed an increase in their knowledge, skills and competences in addiction medicine throughout their tenure in medical school, but their interest in working with addicted patients decreased over the same period.

Importantly, the response rate decreased during follow-up (98 second-year, 75 fourth-year, and 34\% sixthyear). There may be a selection bias, since those with an interest in addiction medicine may be more likely to respond. In addition, self-report measures on skills and attitudes may tend to over-evaluate personal skills [32]. As a result, these findings may be an overestimation of competencies and interest in addiction medicine among students. Finally, the paper lacks a clear description of addiction medicine topics and training methods covered in the curriculum, as well as a description of the amount of hours spent on addiction medicine training.

Four studies investigated the effects of addiction medicine programs for residents. One study assessed the effect of addiction medicine training in the internal medicine residency [40] and one in psychiatry [41], one study assessed addiction medicine training for chief residents from various residency training programs [37], and 


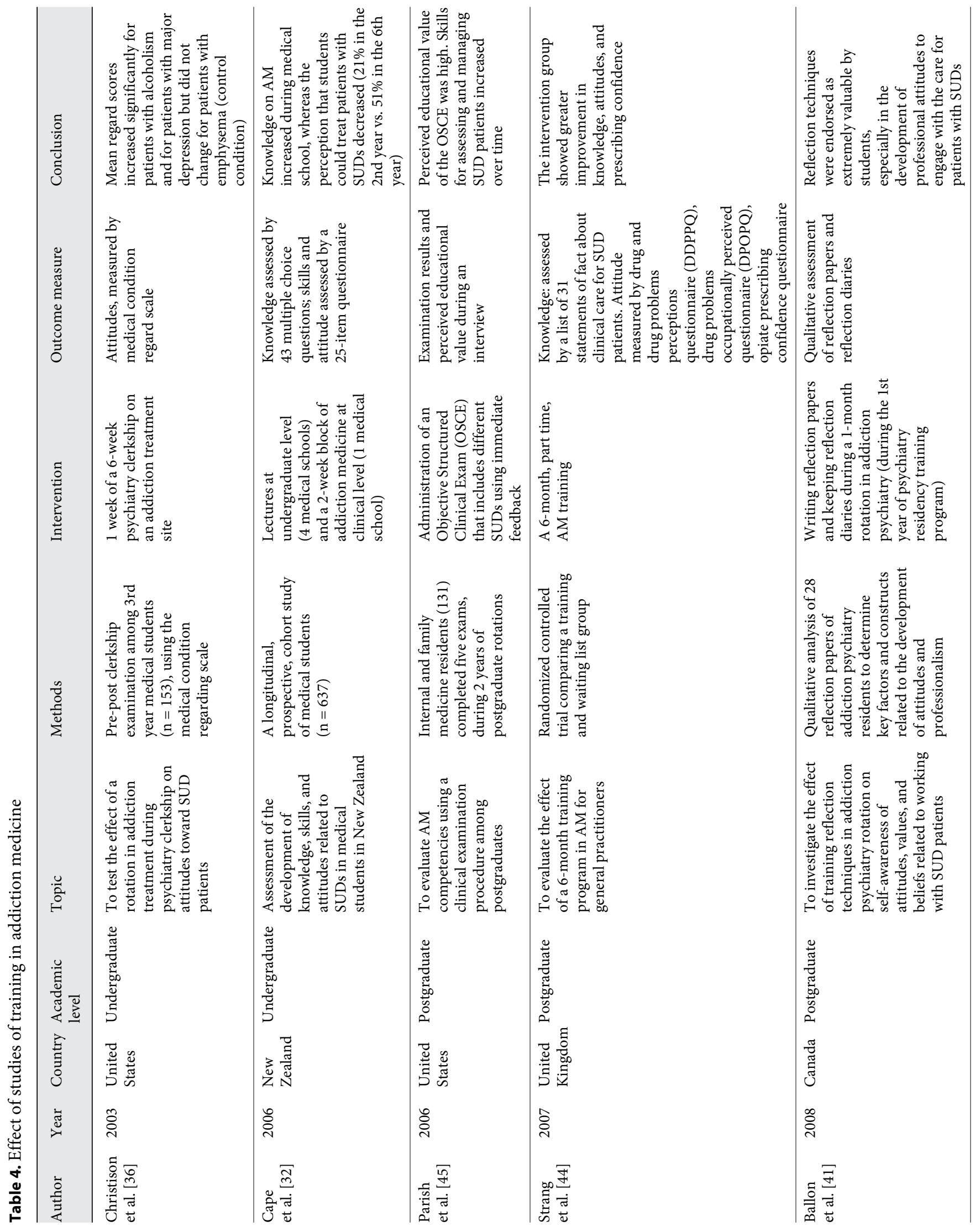




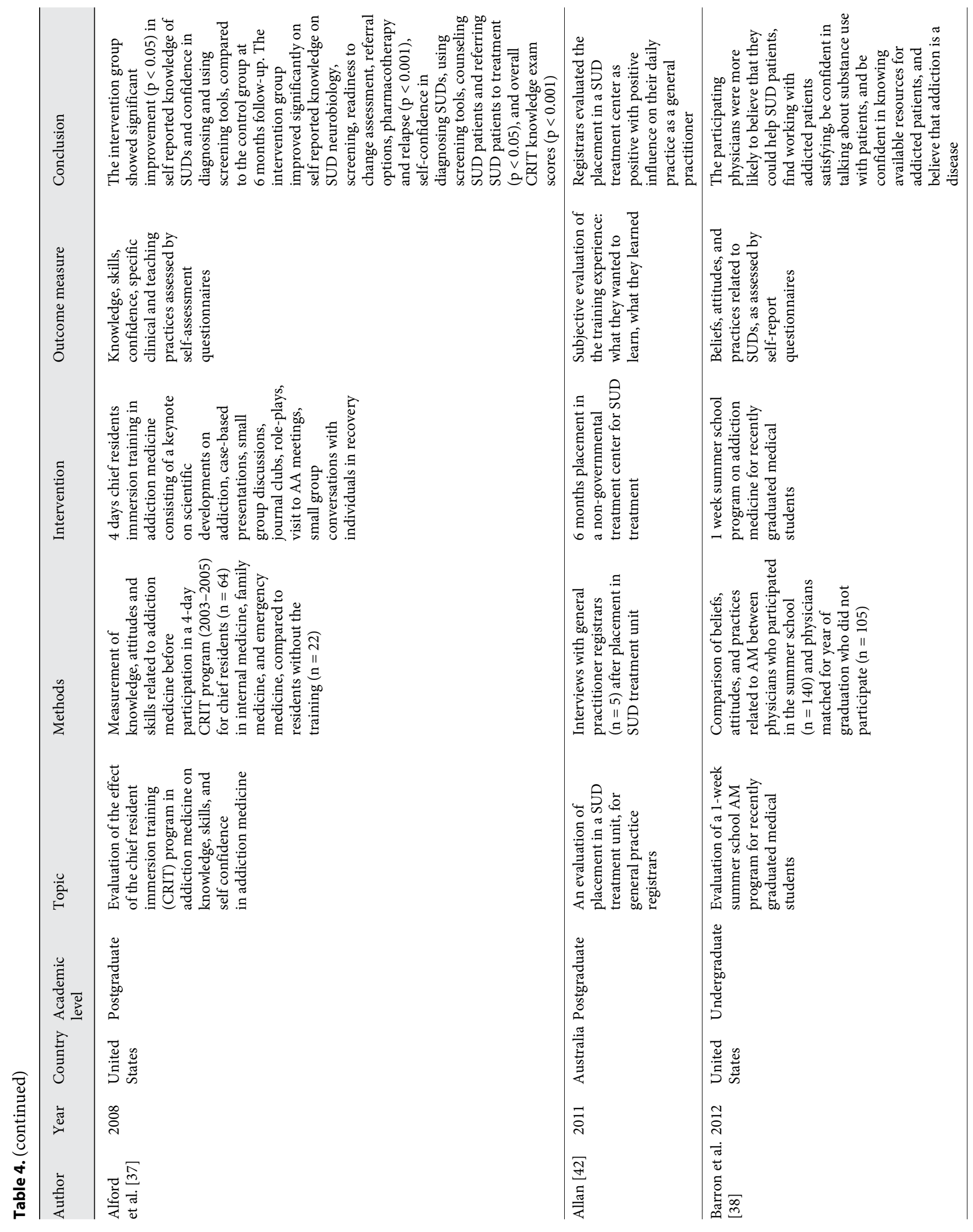




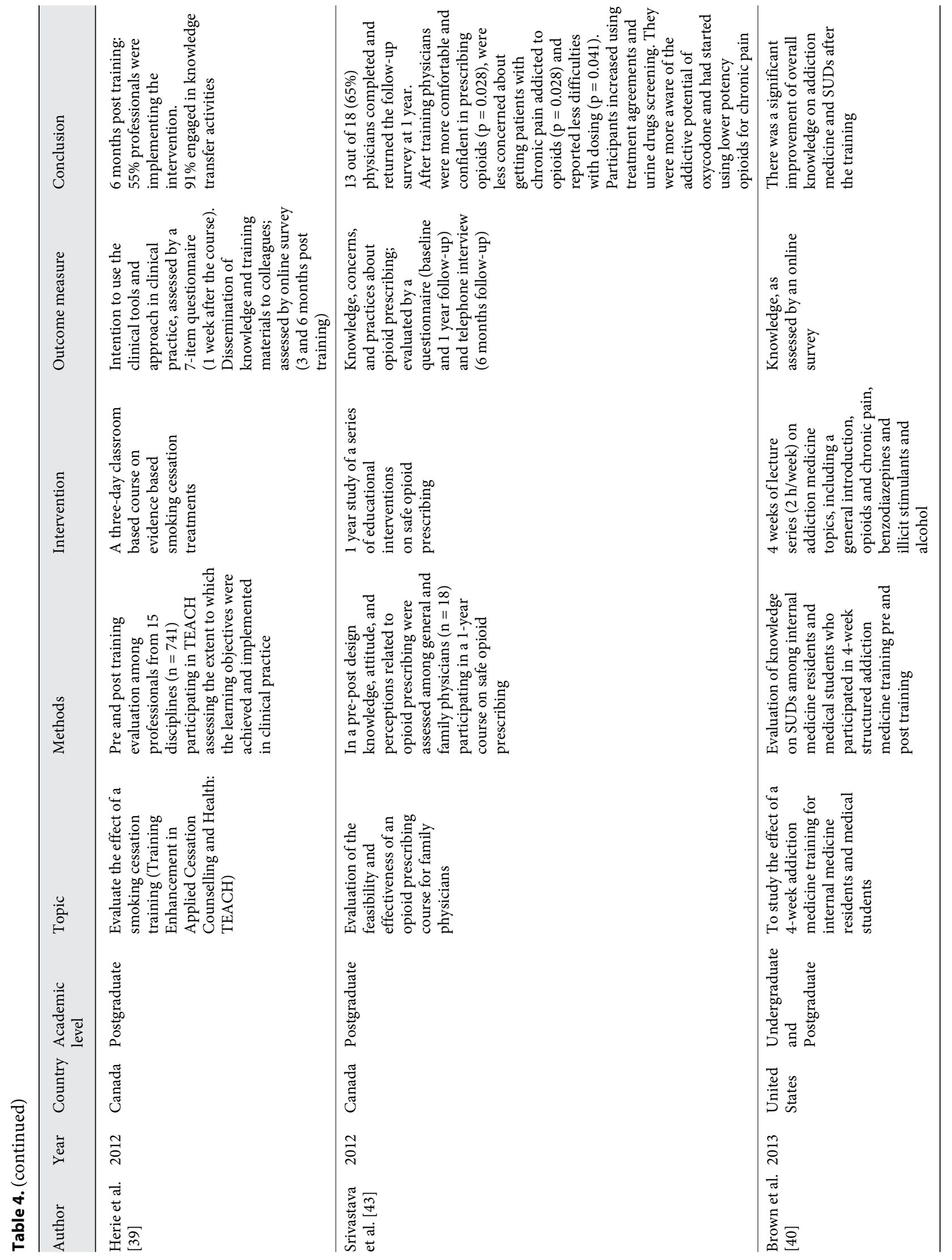


another study was about the effect of a Substance Abuse Objective Structured Clinical Examination (OSCE) for residents [45]. These studies generally show that training residents in addiction medicine can have positive effects on knowledge, skills, and attitudes related to SUDs.

Brown et al. found that a four-week structured addiction medicine curriculum significantly increased knowledge on addiction medicine among internal medicine residents $(n=20)$ [40]. Addiction medicine knowledge was assessed using a 20-item questionnaire in a repeated measures design. Psychometric properties of this instrument (reliability and validity) are unknown. This study was also underpowered with only 20 of 36 participants completing all questionnaires and lacked a control group. Moreover, besides residents, medical students also participated in the course. No separate analyses were performed for these groups. Therefore, it is not possible to draw firm conclusions about the efficacy of this training program for internal medicine residents.

Ballon et al. reported on the effectiveness of reflection methods in addiction psychiatry training in order to develop professional attitudes toward SUD patients [41]. In a qualitative analysis of reflection papers of the residents at the end of a 1-month addiction psychiatry rotation $(\mathrm{n}=28)$, they observed that the residents endorsed reflection techniques as extremely valuable to develop professional attitudes and help to effectively engage with addicted patients [41]. The qualitative analysis fits well with the focus on reflection skills and attitudes. However, it remains to be studied whether these observations relate to more professional attitudes to SUD patients in real life and contribute to improved care for these patients.

Alford et al. reported on an addiction medicine training program for chief residents. The program focused on assessment and management of SUDs. The program was effective in improving clinical and teaching practices in chief residents $(n=64)$ from various residency training programs (internal medicine, family medicine, emergency medicine) as assessed by self-assessment questionnaires [37]. However, the study lacked statistical power, since the sample size, especially in the control group not receiving the integrated training program $(\mathrm{n}=22)$, was rather small.

Parish et al. studied the performance of third-year residents with a prior training in addiction medicine $(\mathrm{n}=$ $131)$, from internal medicine $(\mathrm{n}=107)$ and family medicine $(\mathrm{n}=24)$ in SUDs OSCE [45]. The OSCE consisted of 5 stations with addiction cases (alcohol dependence, methadone maintenance treatment, cocaine dependence, poly drug use). The case scenarios were developed by ex- perts in primary care and addiction medicine, based on substance use competencies recommended for primary care physicians [63]. The evaluators were faculty members from internal medicine, family medicine, and psychiatry. They also gave direct feedback during the examination. In all 5 stations, all the participants performed better in general communication rather than assessment or management. Participants who had completed some training in addiction medicine $(\mathrm{n}=64)$ and who had attended the 12-steps meeting $(n=83)$ performed better compared to those without any experience with the care for SUD patients. Moreover, participants improved their performance during the OSCE over time. The authors emphasized the moderate reliability of the clinical ratings, given the differences in styles of the raters, and the wide range of skills assessed at the different stations. On the other hand, these clinical assessments may be more suitable to assess clinical skills and competencies than written assessments, which mainly test knowledge.

Four studies assessed the effect of addiction medicine training for general practitioners. Allan et al. reported on the effect of a skills training program for general practitioners registrars [42]. The participants were offered the opportunity for placement in a community drug and alcohol treatment unit, comprising a detoxification unit and rehabilitation program. At the evaluation, the participating registrars $(n=5)$ perceived the training program as useful. However, a more systematic assessment of an effect of the training program was lacking and the sample size was rather small.

Strang et al. evaluated the effect of a 6-month training course in addiction medicine on attitudes toward substance use disorder patients among general practitioners $(\mathrm{n}=112)$ [44]. General practitioners interested in the training were randomized into a training group $(n=63)$ and a waiting list group $(n=49)$. The training consisted of regional, tutor-led, conferences in small groups. Knowledge was assessed two times (first and final day of training) using 31 true/false statements. Attitudes were evaluated using the Drug and Drug Problems Perceptions Questionnaire. Self confidence in prescribing opiates (methadone, buprenorphine, lofexidine) was also assessed by questionnaires. The study showed that the training group felt less constraints in treating SUDs as compared to the waiting list group [44].

One article described the effect of a smoking cessation program for health care workers (Training Enhancement in Applied Cessation Counseling and Health: TEACH) [39]. The program consisted of online and classroombased courses and addressed advocacy, individual cogni- 
tive behavioral treatment, group treatment, motivational interviewing, pharmacotherapy, and harm-reduction strategies. Participants $(n=741)$ were health care professionals (including dentists, dietician, general practitioners, family physicians, occupational therapists, pharmacists, physiotherapists, psychologists, nurses, respiratory therapists, social workers, specialist physicians). After training, over $50 \%$ of the participants who responded to the 6 months follow-up survey $(n=455)$ reported they implemented the knowledge and skills they got from the course in their clinical work. More than $90 \%$ of the participants reported that they shared their knowledge with colleagues, students, friends or family [39]. The study lacked a randomized controlled design and relied fully on self-report. Moreover, the participants of this study were from various professional backgrounds. Therefore, these results may be biased and should be interpreted with caution.

Srivastava et al. reported on the effectiveness of a training program on improving skills and practices of prescribing opioids for general or family physicians. The training program was a one-year training program, consisting of workshops, lectures and case discussions, accompanied by video case conferences and clinical support. They assessed the knowledge, concerns, and practices regarding opioid prescribing using self-assessment questionnaires (confidence, comfort, satisfaction, and expectation of a positive outcome) and a telephone interview [43]. The questionnaire was delivered 2 times (before and after the training) and the telephone interview at 6 months. They found that after a 1-year course on opioid prescribing, participants $(n=13)$ were less concerned that patients would develop opioid dependent, were more confident in prescribing opioids, and were more aware of the addictive potential of oxycodone, than at baseline [43]. From the telephone interview, the participants reported a change in their clinical practice (increased use of treatment agreements and urine drug screening). Similar to the other studies, the design of this study was not randomized or controlled, the study relied on self-report and was largely underpowered.

Taken together, these studies on the effect of addiction medicine training showed that training in addiction medicine can be effective in improving knowledge, attitudes and skills related to addiction medicine at various academic levels (undergraduate, postgraduate resident and general practitioner level). Though the results of these studies are encouraging, most of these studies are hampered by a lack of methodological rigor. For example, most studies did not have randomized controlled designs

Effectiveness and Organization of

Addiction Medicine Training and lacked long-term assessments and assessment of real clinical behavior and competencies. Moreover, we did not encounter any studies on the effect of addiction medicine training at the specialist level.

\section{Discussion}

The current review summarizes scientific publications on the development of addiction medicine training over the past fifteen years. There has been a gradual increase in the number of published papers on addiction medicine training over the past fifteen years. Of special interest is the special issue of Substance Abuse in 2011. This may suggest an increased international interest and activity in the development of addiction medicine training and increased availability of addiction medicine curricula.

Indeed, the need for development of addiction medicine training programs is internationally recognized (see table 1). Given the high prevalence of substance use disorders and its commonly co-occurring physical and psychiatric disorders and complications, all medical doctors should have basic competences in addiction medicine $[18,19,58,60]$. The nine papers that describe the training needs for training in addiction medicine cover a broad range of survey studies from the undergraduate to the post-graduate level. These papers indicate that there is generally a lack of addiction medicine teaching at undergraduate level and addiction medicine teaching hours are half of that of other chronic disorders like hypertension or diabetes [27]. Moreover, most students that graduate indicate that they do not know how to treat addicted patients, whereas they report that they do for these other chronic conditions. At the postgraduate level, addiction medicine training is generally available within psychiatry and family medicine [47]. However, in almost half of other postgraduate medical training curricula, no time is allocated to topics related to addiction medicine [47]. This is in line with a number of expert opinion statements published over the past couple of years, arguing that there is a lack of high standard addiction medicine training programs at various academic levels of medical education [64-71].

Several studies describe the development of such training programs at various levels (table 2). The nine articles describing national initiatives on the development of addiction medicine curricula indicate that these curricula vary widely in terms of organization, certification and content (see also table 2). The learning objectives of undergraduate addiction medicine training are recom- 
mended to include: (1) to improve knowledge of addiction medicine, (2) to induce a positive attitude toward SUDs and SUD patients, and (3) to develop a sense of responsibility to treat SUD patients $[54,55]$. Addiction medicine curricula should therefore have a competencybased approach [18, 19, 23, 50, 54, 55, 59, 64, 65, 67, 68]. The addiction medicine competencies that are outlined in these papers commonly cover the following four domains: screening, prevention and brief interventions of substance use disorders; assessment and diagnosis of substance use disorders; management and treatment of substance use disorders (e.g. emergency situations including intoxication and withdrawal, continuing treatment including relapse prevention and rehabilitation); assessment, management, and referral of medical, surgical, and psychiatric complications related to alcohol and substance use disorders, the care for special populations and neuroscience and genetics $[54,55,69,71,72]$ (see also table 3).

The topics outlined here are indeed in line with a UKinitiative on undergraduate training in addiction medicine [73-75]. Within this project, a consensus guideline was first developed on how to integrate addiction medicine training into the undergraduate curriculum. Second, an implementation guideline was developed. By doing so, basic addiction medicine training has been established in all medical schools in the United Kingdom [74, 75].

Previous work by Miller et al. [18] and Polydorou et al. [19] identified several barriers in the development of addiction medicine training curricula in medical education: a lack of uniformity between universities and countries, a lack of continuous training from undergraduate to postgraduate levels and finally several barriers to implementation, once a curriculum is designed (e.g. competition for time slots, lack of well-trained trainers, lack of role models). Based on these barriers, they recommended the development of a guideline for establishing addiction medicine curricula for different academic levels. Miller and Polydorou also mention the need of physician role models in addiction medicine.

The publications on initiatives on the development of addiction medicine curricula included in this review mostly come from Western countries (predominantly from the United States) where addiction medicine training is commonly embedded within psychiatric training programs at the undergraduate level and at the postgraduate level during psychiatric rotations and psychiatric residency $[18,19,36,41,47,48,51,54,55,57,60]$. For example, undergraduate medical students in the United States should follow 1 week rotation in addiction treat- ment facility during their psychiatric clerkship [36]. In Canada, there is a one-month required rotation in addiction for the first-year postgraduate psychiatric residents [41]. Surveys in the United States also found that addiction medicine training is usually provided by the department of psychiatry $[47,48]$. In several countries, such as the United States and Australia, addiction psychiatry is the medical specialty dedicated to the care for substance use disorder patients $[53,56]$. However, in other countries, addiction medicine is a specialty by itself and in several countries care for addicted patients is carried out by general practitioners or other medical specialists. Whether a country needs addiction medicine as a specialty will likely depend on the local situation and organization of the health system.

A more universal approach to the legislation of addiction medicine specialists or addiction psychiatrists could further improvise the functions of this field and boost career perspectives for doctors specializing in addiction medicine and contribute to higher standards of care for addicted patients. International invitational conferences, such as the European Conference on Addiction Medicine Training organized by the Radboud University in September 2014, are needed in order to achieve a more universal approach internationally.

Several experts in the field of addiction medicine have suggested how to move the field forward. First, addiction medicine should get the same priority as other chronic diseases do [64, 70,71]. As such, it must be integrated into the core of medical curricula $[64,65,67,68,70,71]$. Second, faculty members should enhance their competencies in addiction medicine both in clinical teaching and practice $[64,66,70]$. Third, it is suggested that academic medical centers should develop specialized addiction medicine divisions or programs [67-70]. This will increase attractiveness and career perspectives for young professionals. Moreover, it will contribute to professionalization of the field. Fourth, collaboration between addiction specialist and other medical specialist is crucial to further the field of addiction medicine [64, 67-69]. Finally, special attention should be given to substance abuse screening and management at the level of primary care $[65,66,68,70,71]$.

Several studies included in this review show that addiction medicine training programs at all academic levels (undergraduate, postgraduate, specialist) can be effective in increasing knowledge about, improving professional attitudes toward and clinical care for SUD patients (table 4). Moreover, addiction medicine training may also increase physician's interest to become involved in the 
field of addiction medicine and work with these patients $[36,38]$. Though the results of these studies are encouraging, most of these studies did not have a randomized controlled designs and lacked long-term assessments and assessment of real clinical behavior and competencies. Moreover, we did not encounter any studies on the effect of addiction medicine training at specialist level. Therefore, well-designed effect studies are needed in order to clarify the most effective way of training addiction medicine at various academic levels, in order to efficiently improve knowledge, skills and attitudes of medical doctors at all academic levels. Such studies could provide input to develop international guidelines for the development of more uniform addiction medicine curricula.

Several instruments have been developed to customize addiction medicine curricula to local situations. For example, the TNA (as developed by the NIDA) can be used to prioritize training needs, in order to tailor the curriculum to local situations [23]. Similarly, the assessment of perceptions on addiction can provide input for reflection and development of professional attitudes toward addicted patients [36, 76, 77].

The current review should be seen in the light of its limitations. It is important to note that not all international initiatives on the development of addiction medicine curricula are published in the international scientific literature. Most of the published studies included here, come from Western countries, mainly the United States,
Canada, Australia and some European countries (the United Kingdom, Germany, and Netherlands). As such, the current review should not be considered a complete overview of all international curricula on addiction medicine.

To summarize, the current review provides a summary of publications on addiction medicine training programs established over the past fifteen years. The topics and competencies, as well as the evidence for the effect of such training programs are summarized and can be used to further improve existing initiatives on addiction medicine training and help establish new addiction medicine training programs. It is important that training in addiction medicine will get the same priority as other chronic diseases in medical curricula. Faculty development and a clear policy concerning (international) certification of addiction medicine curricula are essential to further improve addiction medicine training and improve the care for addicted patients.

In line with the limited number of (well-designed) studies on the development addiction medicine training, it is important that new and existing initiatives on developing addiction medicine training are properly monitored and results are published. This would further the field and help to establish addiction medicine training worldwide. One of the challenging questions remains as to how to adapt addiction medicine curricula to different settings by taking into account the local context and training needs.

\section{References}

1 Leshner AI: Addiction is a brain disease, and it matters. Science 1997;278:45-47.

2 Smith DE: The process addictions and the new ASAM definition of addiction. J Psychoactive Drugs 2012;44:1-4.

3 Rehm J, Patra J, Degenhardt L: Atlas on substance use (2010): Resources for the prevention and treatment of substance use disorders. Psychoactive substance use: epidemiology and burden of disease. Genève, World Health Organization, 2010.

4 UNODC: World drug report. Vienna, United Nations Office on Drugs and Crime, 2012.

5 Rees G, Day E: Addiction to prescription drugs. Prescriber 2014;25:5-6.

6 Drugs: New psychoactive substances and prescription drugs: twelfth report of session 2013-14. London, House of Commons Home Affairs Committee, 2013.

7 Degenhardt L, Whiteford HA, Ferrari AJ, Baxter AJ, Charlson FJ, Hall WD, Freedman G, Burstein R, Johns N, Engell RE, Flaxman A, Murray CJ, Vos T: Global burden of disease attributable to illicit drug use and depen- dence: findings from the global burden of disease study 2010. Lancet 2013;382:1564-1574.

$\checkmark 8$ Eisenberg S: Psychiatric comorbidity in the addictions treatment setting: assessment, diagnosis, and treatment. Am J Psychiatr Rehabil 2001;5:108-130.

-9 Basu D, Sarkar S, Mattoo SK: Psychiatric comorbidity in patients with substance use disorders attending an addiction treatment center in India over 11 years: case for a specialized 'dual diagnosis clinic'. J Dual Diagn 2013;9:23-29.

10 van de Glind G, Van Emmerik-van Oortmerssen K, Carpentier PJ, Levin FR, Koeter MW, Barta C, Kaye S, Skutle A, Franck J, Konstenius M, Bu ET, Moggi F, Dom G, Demetrovics $Z$, Fatséas $M$, Schillinger A, KapitányFövény $M$, Verspreet $S$, Seitz A, Johnson B, Faraone SV, Ramos-Quiroga JA, Allsop S, Carruthers S, Schoevers RA; Iasp Research Group, van den Brink W: The international ADHD in substance use disorders prevalence (IASP) study: background, methods and study population. Int J Methods Psychiatr Res 2013; DOI: 10.1002/mpr.1397.
1 Carpentier PJ, Knapen LJM, van Gogh MT, Buitelaar JK, De Jong CAJ: Addiction in developmental perspective: influence of conduct disorder severity, subtype, and attention-deficit hyperactivity disorder on problem severity and comorbidity in adults with opioid dependence. J Addict Dis 2012;31:4559.

12 O’Shea RS, Dasarathy S, McCullough AJ: Alcoholic liver disease. Hepatology 2010;51: 307-328.

13 Ruidavets JB, Ducimetière P, Evans A, Montaye $M$, Haas $B$, Bingham A, Yarnell J, Amouyel P, Arveiler D, Kee F, Bongard V, Ferrières J: Patterns of alcohol consumption and ischaemic heart disease in culturally divergent countries: the prospective epidemiological study of myocardial infarction (PRIME). BMJ 2010;341:c6077.

$>14$ Mukamal KJ, Tolstrup JS, Friberg J, Jensen G, Grønbaek M: Alcohol consumption and risk of atrial fibrillation in men and women: the Copenhagen city heart study. Circulation 2005;112:1736-1742.
Effectiveness and Organization of Addiction Medicine Training 
15 Lough ME: Wernicke's encephalopathy: expanding the diagnostic toolbox. Neuropsychol Rev 2012;22:181-194.

16 MacRae R, Cox S: Meeting the needs of people with alcohol related brain damage: a literature review on the existing and recommended service provision and models of care. Scotland, Dementia Services Development Centre, Department of Applied Social Science, Faculty of Human Sciences, University of Stirling, 2003.

17 Gilchrist G, Morrison DS: Prevalence of alcohol related brain damage among homeless hostel dwellers in Glasgow. Eur J Public Health 2005; 15:587-588.

$\checkmark 18$ Miller NS, Sheppard LM, Colenda CC, Magen $\mathrm{J}$ : Why physicians are unprepared to treat patients who have alcohol- and drug-related disorders. Acad Med 2001;7:410-418.

19 Polydorou S, Gunderson EW, Levin FR: Training physicians to treat substance use disorders. Curr Psychiatry Rep 2008;10:399404.

20 Tang YL, Hao W: Improving drug addiction treatment in China. Addiction 2007;102:10571063.

21 Fernando SM, Deane FP, McLeod HJ: Sri Lankan doctors' and medical undergraduates' attitudes towards mental illness. Soc Psychiatry Psychiatr Epidemiol 2010;45:733739.

22 Gilchrist G, Moskalewicz J, Slezakova S, Okruhlica L, Torrens M, Vajd R, Baldacchino A: Staff regard towards working with substance users: a European multi-centre study. Addiction 2011;106:1114-1125.

23 Pinxten WJ, De Jong C, Hidayat T, Istiqomah AN, Achmad YM, Raya RP, Norviatin D, Siregar IM: Developing a competence-based addiction medicine curriculum in Indonesia: the training needs assessment. Subst Abus 2011;32:101-107.

- 24 Frost-Pineda K, VanSusteren T, Gold MS: Are physicians and medical students prepared to educate patients about alcohol consumption? J Addict Dis 2004;23:1-13.

-25 Soyka M, Gorelick DA: Why should addiction medicine be an attractive field for young physicians? Addiction 2009;104:169-172.

26 De Jong CA, Van De Wetering BJ: Addiction medicine is an attractive field for young physicians - a call for a European initiative for the training in addiction medicine. Addiction 2009;104:1258-1259.

-27 Strobel L, Schneider NK, Krampe H, Beißbarth T, Pukrop T, Anders S, West R, Aveyard P, Raupach T: German medical students lack knowledge of how to treat smoking and problem drinking. Addiction 2012;107: 1878-1882.

28 Wakeman SE, Baggett MV, Pham-Kanter G, 43 Campbell EG: Internal medicine residents' training in substance use disorders: a survey of the quality of instruction and residents' self-perceived preparedness to diagnose and treat addiction. Subst Abus 2013;34:363370 .
29 Tang YL, Wiste A, Mao PXC, Hou YZ: Attitudes, knowledge, and perceptions of Chinese doctors toward drug abuse. J Subst Abuse Treat 2005;29:215-220.

30 Barry CL, McGinty EE, Pescosolido BA, Goldman HH: Stigma, discrimination, treatment effectiveness, and policy: public views about drug addiction and mental illness. Psychiatr Serv 2014;65:1269-1272.

31 Broyles LM, Binswanger IA, Jenkins JA, Finnell DS, Faseru B, Cavaiola A, Pugatch M, Gordon AJ: Confronting inadvertent stigma and pejorative language in addiction scholarship: a recognition and response. Subst Abus 2014:35:217-221.

32 Cape G, Hannah A, Sellman D: A longitudinal evaluation of medical student knowledge, skills and attitudes to alcohol and drugs. Addiction 2006;101:841-849.

33 Robb N: Teaching on addiction issues lacking in medical school, specialists told. CMAJ 1998;158:640-641.

-34 Keller DS, Dermatis H: Current status of professional training in the addictions. Subst Abus 1999;20:123-140.

-35 O’Brien S, Cullen W: Undergraduate medical education in substance use in Ireland: a review of the literature and discussion paper. Ir J Med Sci 2011;180:787-792.

36 Christison GW, Haviland MG: Requiring a one-week addiction treatment experience in a six-week psychiatry clerkship: effects on attitudes toward substance-abusing patients. Teach Learn Med 2003;15:93-97.

- 37 Alford DP, Bridden C, Jackson AH, Saitz R, Amodeo M, Barnes HN, Samet JH: Promoting substance use education among generalist physicians: an evaluation of the chief resident immersion training (CRIT) program. J Gen Intern Med 2009;24:40-47.

38 Barron R, Frank E, Gitlow S: Evaluation of an experiential curriculum for addiction education among medical students. J Addict Med 2012;6:131-136.

39 Herie M, Connolly H, Voci S, Dragonetti R, Selby P: Changing practitioner behavior and building capacity in tobacco cessation treatment: the TEACH project. Patient Educ Couns 2012;86:49-56.

40 Brown AT, Kolade VO, Staton LJ, Patel NK: Knowledge of addiction medicine among internal medicine residents and medical students. Tenn Med 2013;106:31-33.

41 Ballon BC, Skinner W: 'Attitude is a little thing that makes a big difference': reflection techniques for addiction psychiatry training. Acad Psychiatry 2008;32:218-224.

42 Allan J: Advanced rural skills training - the value of an addiction medicine rotation. Aust Fam Physician 2011;40:927-929.

43 Srivastava A, Kahan M, Jiwa A: Prescription opioid use and misuse: piloting an educational strategy for rural primary care physicians. Can Fam Physician 2012;58:e210e216.

44 Strang J, Hunt C, Gerada C, Marsden J: What difference does training make? A random- ized trial with waiting-list control of general practitioners seeking advanced training in drug misuse. Addiction 2007; 102:16371647.

45 Parish SJ, Ramaswamy M, Stein MR, Kachur EK, Arnsten JH: Teaching about substance abuse with objective structured clinical exams. J Gen Intern Med 2006;21:453-459.

46 Popay J, Roberts H, Sowden A, Petticrew M, Arai L, Rodgers M, Britten N, Roen K, Duffy $S$ : Guidance on the conduct of narrative synthesis in systematic reviews: ESRC methods programme, 2006.

47 Fleming MF, Manwell LB, Kraus M, Isaacson $\mathrm{JH}, \mathrm{Kahn}$ R, Stauffacher EA: Who teaches residents about the prevention and treatment of substance use disorders? A national survey. J Fam Pract 1999;48:725-729.

48 Kraus ML, Isaacson JH, Kahn R, Mundt MP, Manwell LB: Medical education about the care of addicted incarcerated persons: a national survey of residency programs. Subst Abus 2001;22:97-104.

$\checkmark 49$ Kahan M, Midmer D, Wilson L, Liu E: Faculty rating of learning objectives for an undergraduate medical curriculum in substance abuse. Subst Abus 2001;22:257-263.

50 Abrams Weintraub T, Saitz R, Samet JH: Education of preventive medicine residents: alcohol, tobacco, and other drug abuse. Am J Prev Med 2003;24:101-105.

51 Waldbaum M, Galanter M, Dermatis H, Greenberg WM: A survey of addiction training in child and adolescent psychiatry residency programs. Acad Psychiatry 2005;29: 274-278.

52 el-Guebaly N, Violato C: The international certification of addiction medicine: validating clinical knowledge across borders. Subst Abus 2011;32:77-83.

53 Galanter M, Dermatis H, Calabrese D: Residencies in addiction psychiatry: 1990 to 2000, a decade of progress. Am J Addict 2002;11: 192-199.

54 Renner JA Jr, Quinones J, Wilson A: Training psychiatrists to diagnose and treat substance abuse disorders. Curr Psychiatry Rep 2005; 352-359.

55 Renner JA Jr: How to train residents to identify and treat dual diagnosis patients. Biol Psychiatry 2004;56:810-816.

56 Lubman D, Jurd S, Baigent M, Krabman P: Putting 'addiction' back into psychiatry: The RANZCP section of addiction psychiatry. Australas Psychiatry 2008;16:39-43.

57 Iannucci R, Sanders K, Greenfield SF: A 4-year curriculum on substance use disorders for psychiatry residents. Acad Psychiatry 2009;33:60-66.

58 Rigotti NA, Bitton A, Richards AE, Reyen M, Wassum K, Raw M: An international survey of training programs for treating tobacco dependence. Addiction 2009;104: 288-296.

59 De Jong C, Luycks L, Delicat JW: The master in addiction medicine program in the Netherlands. Subst Abus 2011;32:108-114. 
-60 Tontchev GV, Housel TR, Callahan JF, Kunz KB, Miller MM, Blondell RD: Specialized training on addictions for physicians in the United States. Subst Abus 2011;32:8492.

61 Haber PS, Murnion BP: Training in addiction medicine in Australia. Subst Abus 2011;32: 115-119.

62 Roche AM, Parle MD, Saunders JB: Managing alcohol and drug problems in general practice: a survey of trainees' knowledge, attitudes and educational requirements. Aust N Z J Public Health 1996;20:401-408.

63 Fiellin DA, Butler R, D’Onofrio G, Brown RL, O'Connor PG: The physician's role in caring for patients with substance use disorders: implications for medical education and training. Subst Abus 2002;23(3 suppl):207-222.

64 Dove HW: Postgraduate education and training in addiction disorders. Defining core competencies. Psychiatr Clin North Am 1999; 22:481-488, xi.

65 Klamen DL: Education and training in addictive diseases. Psychiatr Clin North Am 1999; 22:471-480, xi.
66 el-Guebaly N, Crockford D, Cirone S, Kahan M: Addiction medicine in Canada: challenges and prospects. Subst Abus 2011;32:93100.

67 Wyatt SA, Vilensky W, Manlandro JJ Jr, Dekker MA 2nd: Medical education in substance abuse: from student to practicing osteopathic physician. J Am Osteopath Assoc 2005;105(6 suppl 3):S18-S25.

68 Wyatt SA, Dekker MA: Improving physician and medical student education in substance use disorders. J Am Osteopath Assoc 2007; 107(9 suppl 5):ES27-ES38.

69 Lande RG, Wyatt SA, Przekop PR Jr: Addiction medicine: a model osteopathic medical school curriculum. J Am Osteopath Assoc 2010;110:127-132.

70 O'Connor PG, Nyquist JG, McLellan AT: Integrating addiction medicine into graduate medical education in primary care: the time has come. Ann Intern Med 2011;154:56-59.

71 Rasyidi E, Wilkins JN, Danovitch I: Training the next generation of providers in addiction medicine. Psychiatr Clin North Am 2012;35: 461-480.
72 Samet JH, Galanter M, Bridden C, Lewis DC: Association for medical education and research in substance abuse. Addiction 2006; 101:10-15.

73 Substance misuse in the undergraduate medical curriculum. London, The International Centre for Drug Policy, 2007.

74 Carroll J, Goodair C, Chaytor A, Notley C, Ghodse H, Kopelman P: Substance misuse teaching in undergraduate medical education. BMC Med Educ 2014; 14:34

75 Notley C, Goodair C, Chaytor A, Carroll J, Ghodse H, Kopelman P: Report of the substance misuse in the undergraduate medical curriculum project in England. Drug Educ Prev Policy 2014;21:173-176.

76 Matthews J, Kadish W, Barrett SV, Mazor K, Field D, Jonassen J: The impact of a brief interclerkship about substance abuse on medical students' skills. Acad Med 2002;77:419426.

77 James BO, Omoaregba JO: Nigerian medical students' opinions about individuals who use and abuse psychoactive substances. Subst Abus 2013;7:109-116. 